\title{
VIGIAR E ASSISTIR: REFLEXÕES SOBRE O DIREITO À ASSISTÊNCIA DA "ADOLESCÊNCIA POBRE"1
}

\author{
João Silveira Muniz Neto² \\ Aluísio Ferreira de Lima \\ Luciana Lobo Miranda \\ Luara da Costa França \\ Universidade Federal do Ceará, Fortaleza-CE, Brasil
}

RESUMO. Neste artigo analisamos a categoria "adolescente pobre" como um conjunto populacional a ser assistido pelo Estado brasileiro, a partir da perspectiva genealógica de Michel Foucault. Desse modo, consideramos a adolescência como uma invenção e efeito de certos exercícios de saber e de poder que a coloca como objeto da assistência social. Tratamos de tecer análises acerca das consequências políticas e de assujeitamento advindas dos Códigos de Menores e do Estatuto da Criança e do Adolescente - ECA. As análises de tais documentos assinalam como sua produção incide sobre uma população específica, produzindo uma identidade que se dirá pobre, gerenciando e produzindo condutas e modos de viver e apresentando formas apropriadas de felicidade, condicionadas à legalidade. Nesse artigo, buscamos analisar a história do pensamento assistencialista acerca do "adolescente pobre" no contexto brasileiro e de como este grupo passou a ser alvo de um conjunto de práticas de Estado e de políticas públicas.

Palavras-chave: Psicologia Social; adolescência; Estatuto da Criança e do Adolescente.

\section{TO WATCH AND TO ATTEND: REFLECTIONS ON LEGAL ASSISTANCE OF "POOR ADOLESCENT"}

\begin{abstract}
In this article we analyze the category "poor adolescent" as a whole population to be attended by Brazilian government from the standpoint of Michel Foucault's genealogical perspective. Thus, we consider adolescence as an invention and effect of certain exercises of knowledge and power placing it as the object of Social Assistance. We try to make analysis about the political consequences and the subjection resulting on Minors Code and the Statute of Children and Adolescents - ECA. The analysis of such documents indicate how their production focus on a specific population, producing an identity that will say poor, managing and producing behaviors, ways of living, with appropriate forms of happiness conditional upon the legality. In this article, we aim to link analyzes concerning the history of paternalistic thinking on "poor adolescent" in the Brazilian context and how this group became the target of a set of State practices and public policies.
\end{abstract}

Keywords: Social psychology; adolescence; the statute of the child and adolescent.

\section{VIGILAR Y ASISTIR: REFLEXIONES ACERCA DEL DERECHO A LA ASISTENCIA DE LA "ADOLESCENCIA POBRE"}

RESUMEN. En este artículo analizamos la categoría "adolescente pobre", como un grupo de la población a ser asistida por el gobierno brasileño desde la perspectiva genealógica de Michel Foucault. De tal modo, consideramos la adolescencia como una creación y efecto de determinados ejercicios de saber/poder que la coloca como objeto de la Asistencia Social. Hacemos así el análisis de las consecuencias políticas y sujeción resultante del uso de los Códigos de Menores y del Estatuto del Niño y del Adolescente - ECA. El análisis de esos documentos señala como su producción incide en una población específica, produciendo una identidad que se dirá pobre, gestionando y produciendo conductas, y modos de vida, presentando formas apropiadas de felicidad supeditadas a la legalidad. En este artículo, nuestro objetivo es tejer los análisis relativos a la historia del pensamiento de bienestar "adolescente pobre" en el

Apoio e financiamento: Coordenação de Aperfeiçoamento de Pessoal de Nível Superior (CAPES).

2 Endereço para correspondência: Programa de Pós-Graduação em Psicologia, Departamento de Psicologia. Av. da Universidade, 2762 - Área II - Centro de Humanidades Campus do Benfica, CEP 60.020-180 - Fortaleza-CE, Brasil. E-mail: netomuniz15@yahoo.com.br. 
contexto brasileño y cómo este grupo se convirtió en el blanco de una serie de prácticas de Estado y de políticas públicas.

Palabras-clave: Psicología social; adolescente; estatuto del niño y del adolescente.

Este artigo tem como objetivo realizar uma análise de uma maquinaria contemporânea que torna da ordem do natural uma assistência social do Estado a um grupo específico: a adolescência pobre. A partir da perspectiva genealógica, tomada de empréstimo a Michel Foucault (1992), tentaremos expor os regimes de saber e poder que possibilitaram emergir, na governamentalidade atual, uma proteção à adolescência pobre, no sentido de desnaturalizar a tutela como algo natural ou mesmo avanço político. Assim dito, desejamos analisar a história do pensamento assistencialista sobre o "adolescente pobre" no contexto brasileiro e como este grupo passou a ser alvo de de políticas públicas, de políticas de Estado.

Em Foucault, genealogia significa uma atitude de pesquisa, uma atitude que trabalha menos com generalizações totalizadoras e mais com fragmentos, com descontinuidades, com o que se diferencia (Candiotto, 2012). Não apreende verdades ou falsidades, mas busca a "verificabilidade que possa servir de ponto de partida para novos problemas, novas pesquisas" (Lobo, 2012, p.17). Ao conferir um estatuto ontológico à história, priorizando suas contingências e não uma pretensa universalidade, à genealogia foucaultiana torna-se fundamental o "como". As perguntas da pesquisa não partiriam de um por que, nem procuraria na história o início ou a gênese das coisas. Assim, não se questiona por que houve por parte da assistência social um interesse pelo adolescente, mas como o adolescente tornou-se alvo da assistência, quais fios da trama discursiva e não discursiva constituem a adolescência pobre como um grupo a ser tutelado.

Para a genealogia importam as condições de possibilidade que permitem que determinado acontecimento surja como invenção de uma dada época. Entendemos, desta maneira, a genealogia como um pensamento filosófico e uma prática teórica, enquanto produção de verdades-meio, "uma ontologia histórica das subjetivações, de uma análise não linear que aborde a emergência de práticas e a construção de discursos" (Lobo, 2012, p.16), a partir da postura metodológica de um ceticismo sistemático no que concerne aos universais antropológicos (Candiotto, 2012).

Para a problematização da emergência de uma adolescência pobre, objeto da assistência social, partimos da desconfiança em relação a duas grandes questões, a saber: de que os próprios discursos que sustentam e constroem a categoria adolescente são agenciamentos que têm efeitos e decorrências políticas instauradores de dispositivos indicadores de modos de vida e de que a aparente fatalidade do socialmente vulnerável acaba por ajudar a constituir o "adolescente pobre" como alguém a ser assistido.

Tais desconfianças seguem pistas deixadas por Michel Foucault $(1987 ; 2002)$ a partir de sua análise do poder e da governamentalidade. A noção de poder em Foucault, a partir do curso no Collège de France Território, Segurança, População (em 1978) já começa a ser cambiada em direção a uma problemática do governo, compreendido não como simples gestão governamental ou partidária, mas governo concebido a partir da dimensão das técnicas e estratégias direcionadas a dirigir a conduta dos homens. $O$ poder disciplinar, que submetia a constante vigilância os internos de instituições como escolas, quartéis, hospitais, prisões, etc., passa a cambiar-se em um novo exercício de poder, que, atravessando o recinto exclusivo das instituições, passa a preocupar-se com a segurança das populações. Acreditamos que na atualidade não exista propriamente - como no modelo disciplinar - um modelo de internação por excelência, entretanto, operando de forma mais sutil, a institucionalização e a vigilância ainda são características nucleares daquilo a que Michel Foucault (2008) nomeou de dispositivos de segurança. Se a intenção da disciplina era imprimir nos internos a onipresença de uma vigilância sobre os indivíduos (Foucault, 1987), nos dispositivos de segurança 
... vai se trabalhar com o futuro, isto é, a cidade não vai ser concebida nem planejada em função de uma percepção estática que garantiria instantaneamente a perfeição da função, mas vai se abrir para um futuro não exatamente controlado ou controlável, não exatamente medido nem mensurável, e o bom planejamento da cidade vai ser precisamente: levar em conta o que pode acontecer (Foucault, 2008, p. 26).

Nos dispositivos de segurança é central a ideia de risco. A arte de governo do século $X X$ passa a atuar conforme a noção de risco, em oposição à noção de perigo que atravessara o modo de governar no Ocidente até os séculos XVIII e XIX com maior intensidade. O perigo remete ao imponderável, ao acaso, àquilo sobre o qual não há previsibilidade. O risco, ao contrário, "se coloca dentro de uma ordem contida na ação humana deliberada" (Hillesheim \& Cruz, 2007, p. 195), podendo indicar a probabilidade do seu acontecimento a partir das condutas assumidas pelos indivíduos. Assim, a ideia de risco remete à ideia de prevenção. Explica Pontes (2011, p. 22):

No conceito de risco, pode-se perceber que a probabilidade de incidência de uma enfermidade está relacionada aos hábitos individuais e/ou ao meio em que a população está inserida, uma vez que estes aumentam a exposição a agentes nocivos. Desta forma, este conceito possibilita 0 agenciamento de duas formas diferentes de intervenção, uma com foco na população que busca regular a incidência de forma a normalizá-la, outra com foco no indivíduo com objetivo de normatizá-lo.

Neste cenário de governamentalidade, que tem na gestão do futuro a principal peça de sua engrenagem, a preocupação com aquele que ainda não é adulto (criança/jovem) torna-se central. Então a adolescência passou a ser tomada como um importante locus de incidência das práticas de governo a partir do século $X X$ (Gadelha, 1998), sendo então concebida como o futuro do presente, de forma que o terreno da assistência social tornou-se fundamental para o exercício do poder sobre essa população sobretudo sua fração pobre (Gadelha, 2013).

Creditamos relevância ao tema do artigo na medida em que este aponta para as condições de possibilidade da política de assistência social direcionada à adolescência, buscando um território de reflexão que potencializa o sentimento de inquietude diante de construções cristalizadas acerca da adolescência.

$\mathrm{Na}$ estrutura deste trabalho desenhamos um breve panorama sobre o sujeito da assistência social, para a partir daí fazer um afunilamento das condições de possibilidade do "adolescente pobre" como população de risco que, por isso mesmo, requer uma proteção especial, seja por meio do vetor jurídico (códigos específicos remetidos a esta fração populacional) seja através de políticas públicas. Discutimos também acerca do modo como as práticas assistencialistas do Brasil higienista do início do século $X X$ ainda encontram ressonância nas políticas socioassistenciais hodiernas direcionadas à adolescência pobre. Por fim, fazemos um breve cotejo do Estatuto da Criança e do Adolescente (ECA) com os Códigos de Menores de 1927 e 1979 com o intuito de estabelecer rupturas e continuidades acerca desses códigos.

\section{A ASSISTÊNCIA SOCIAL: CONTROLE DAS VIRTUALIDADES}

Muitas das atuais políticas socioassistenciais reclamam para si o status de libertadoras, o que nos permitiria afirmar vivermos tempos de um Estado provedor, que acolhe os mais necessitados, tendo suas ações pautadas pelos objetivos finais de autonomia e de inclusão de todos os indivíduos na sociedade (Benevides, 2011). Viveríamos em um momento no qual a promoção da visibilidade por meio das políticas públicas anunciaria a existência concreta de um avanço em torno da categoria social, estabelecendo diferenças entre a (outrora praticada) caridade e a política socioassistencial praticada atualmente. Esta última, assentada em ideais politicamente corretos e preventivistas, preocupa-se em governar as populações que estão em vulnerabilidade social. No site oficial do Ministério do Desenvolvimento Social e Combate à Fome (MDS), por exemplo, consta que

... a Proteção Social Básica tem como objetivo a prevenção de situações de risco por meio do desenvolvimento de potencialidades e aquisições e o fortalecimento de vínculos familiares e comunitários. Destina-se à população que vive em situação de fragilidade 
decorrente da pobreza, ausência de renda, acesso precário ou nulo aos serviços públicos ou fragilização de vínculos afetivos (discriminações etárias, étnicas, de gênero ou por deficiências, dentre outras) (Brasil, 2012, para.2).

Em uma dimensão ideal, viveríamos em um tempo de frequentes anúncios de mudanças nas práticas públicas a partir do viés da assistência social, porém acreditamos que atualmente vivemos uma hegemonia às avessas, segundo a expressão de Chico de Oliveira, em que todo o aparato político reflete uma forma de administração conservadora, "plasmada pelos limites inerentes à semiperiferia capitalista, em que o avanço nutre-se permanentemente do atraso" (Oliveira, 2010, p. 11). Assim, desconfiados e incomodados em relação à noção socioassistencial que atravessa nossas atuais sociedades e aos benefícios e avanços que ela traria consigo, perguntamos sobre as condições de possibilidade que permitiram a Constituição Federal de 1988 garantir assistência social a "quem dela necessitar" (Brasil, 1988, art. 203).

Para responder a uma questão desta ordem, acreditamos ser importante operar uma volta no tempo-espaço; assim, o local de onde partiremos será a cidade do Rio de Janeiro do início do século $X X$, então capital federal. Neste cenário, irrompiam noções higienistas embasadas em (contestáveis) noções científicas, pululavam médicos, filantropos, juristas e políticos preocupados com o futuro da nação e em dar ao Brasil o status de país civilizado. Neste contexto, alvorecia toda uma idealização binária daquilo que se convencionou chamar de pobre vicioso (que representaria, para o Estado e para o bem comum, um perigo imanente e perene, uma periculosidade (in)comum) ou pobre digno - representante de uma essência; figura que poderia, a despeito de sua condição eminentemente e quase determinista de status social, servir de modelo para o primeiro grupo do binarismo. Ao pobre vicioso estavam anexadas características que tanto 0 marcavam quanto o compunham: periculosidade, criminalidade, inumanidade (Coimbra, 2001).

Foucault (2002) problematiza que até o século XIX ocorreu na governamentalidade europeia aquilo que nomeou de modelo exclusivo da lepra e modelo inclusivo da peste. Ambos os modelos eram acionados conforme a situação extremada de peste ou de lepra. O leproso era excluído do burgo para não contaminar ninguém, processando-se, desta maneira, um controle por meio da exclusão. Na lepra, ao contrário, um controle policialesco e minucioso se exercia dentro de cada moradia, a fim de averiguar se as precauções e recomendações médicas estavam sendo seguidas à risca - quarentena da família, pouca exposição do contaminado, resguardo domiciliar, etc. (Foucault, 1992; 2002). Desde a Idade Média a prática de exclusão dos leprosos foi algo comum no continente europeu, mas "o modelo do indivíduo expulso para purificar a comunidade, acabou desaparecendo, grosso modo, em fins do século XVII - início do século XVIII" (Foucault, 2002, p. 38).

Tal característica includente da governamentalidade é uma das condições de possibilidade para a emergência de um Estado Social, que tem a dupla missão de alargar o mercado consumidor e reduzir as probabilidades de motins e revoltas. Eis o que escreve Castel (2008, p. 45):

\begin{abstract}
A liberdade e o individualismo triunfantes comportam uma face sombria: a individualidade negativa de todos aqueles que se encontram sem vínculos e sem suportes, privados de qualquer proteção e qualquer reconhecimento. $\mathrm{O}$ Estado social foi construído como uma resposta a tal situação.
\end{abstract}

Interessou-nos até aqui pensar o binômio inclusão-exclusão e o possível acoplamento da população pobre a um modelo includente de governamentalidade. Desta maneira, considerando que a própria categoria adolescente (tema que será explorado no próximo tópico) tem toda uma história que sustenta sua emergência enquanto acontecimento e invenção, perguntamos: quais as implicações de uma política de assistência includente dirigida à "adolescência pobre" e quais seus objetivos? Antes, qual a noção que se assume do "adolescente pobre" para que se possa reclamar uma assistência estatal específica a ele?

Sem tentar responder de modo definitivo às perguntas lançadas, acreditamos que a noção que parece sustentar todo 0 aparato 
socioassistencial juvenil é, precisamente, a de que o Estado necessita assistir adolescentes pobres para incorporá-los à lógica constituída e construir uma sociedade mais - por assim dizer includente, com o controle do que não aconteceu ainda e de algo que, convocando-se probabilidades, tem grandes chances de efetuarse (adolescentes pobres causam/são/representam periculosidade). Assim são tomadas como objeto de preocupação não mais, como dantes,

as infrações às normas cometidas pelos sujeitos, mas sim com o que eles poderiam vir a infligir. Ou seja, o controle não será somente sobre o que se é, o que se faz, mas também sobre o que se poderá vir a ser, vir a fazer; sobre as virtualidades, portanto (Foucault, 2002, p. 86).

Foucault, em sua obra "Vigiar e Punir", disserta acerca do caráter virtual que o poder disciplinar-normalizador acaba por compor. Com a "microeconomia de uma penalidade perpétua" (2002, p. 151) operando sobre os indivíduos, a normalização ocupa-se dos indivíduos e não mais dos comportamentos dos indivíduos: "opera-se uma diferenciação que não é a dos atos, mas dos próprios indivíduos, de sua natureza, de suas virtualidades" (Foucault, 2002, p. 151). Desde o século XIX o sistema jurídico ocidental não julga mais o delinquente, mas a própria cota de delinquência que cada um carregaria em si. No Brasil, periculosidade, atrelada ao vetor pobreza desde o início do século XX (Lemos, 2012), torna cada vez mais visível a adolescência, mormente a das camadas mais populares. A adolescência pobre, em um contexto de controle de riscos e prevenção de delinquência, torna-se preocupação central da governamentalidade, pois carregaria em si o gérmen da delinquência.

\section{A EMERGÊNCIA DO “SER” ADOLESCENTE}

Quando iniciamos
pronunciamento acerca da adolescência,
normalmente tendemos a operar em um
raciocínio consensual, de tal maneira que
convocamos os diversos especialistas, os
"experts" (médicos, psicólogos, pedagogos,
juristas e outros) para descrever, esmiuçar,
territorializar a adolescência. Tais enunciados,

na maioria das vezes, parecem partir de algo dado, quase como um axioma, não chegando a refletir acerca de seus mecanismos de definição e de seus dispositivos de invenção e produção de sentido.

Crenças que concebem a adolescência como uma fase do desenvolvimento, um rito de passagem, não podem ser a síntese de uma constatação evidente ou natural. Autores como Castro (2001) discutem a estreita relação entre a Psicologia do Desenvolvimento e o projeto iluminista com sua ideia de progresso, enquanto Coimbra (2001) problematiza o mito do atrelamento da adolescência pobre à violência.

Entendemos que a própria narração acerca da adolescência acaba por produzir uma identidade performativa do adolescente, tal como assinala Butler (2008). Vale ressaltar que o conceito de performatividade utilizado por Butler resulta de uma apropriação da concepção desenvolvida por Austin (1971), ponderando que a linguagem não se limitaria a meras proposições descritivas, mas compreenderia uma ação ou uma situação. Assim, além da função descritiva, a linguagem também teria uma função produtiva, fazendo com que algo se efetive e se realize. Austin chama a essas proposições de performativas. Do mesmo modo, é importante dizer que a apropriação da concepção de performatividade na discussão desenvolvida por Butler (2008) nos interessa porque permite evidenciar como as muitas proposições descritivas funcionam de forma performativa, na medida em que sua enunciação repetida produz o fato antes apenas descrito.

Em direção oposta às teses que defendem o determinismo biológico no desenvolvimento humano, a noção de performatividade implica em assumir que, longe de ser o resultado de uma natureza, as sociedades constroem as normas que regulam e materializam a identidade dos sujeitos, de modo que essas normas regulatórias precisam ser constantemente repetidas e reiteradas para que tal materialização se concretize.

Diante deste contexto, neste trabalho partimos de uma concepção linguísticoperformativa da adolescência, não a compreendendo como uma fase ou um dado processo fisiológico/cultural. Julgando necessário deflagrar a visibilidade do cenário produtivo do território adolescência, bem como 
a centralidade da narração acerca de, que acaba por produzir modulações de, avançamos rumo à postura de desnaturalização de certos discursos biologizantes, e psicologizantes da adolescência que acabam por retroalimentar toda uma gramática identitária. Observemos, por exemplo, na passagem de Calligaris (2000), certa mistificação da adolescência a partir da prescrição de certas normas de funcionamento-expressão-vivência.

necessário problematizar a noção identitárioexistencial, concebendo-a como arranjo contingente aos espaços-tempos discursivos:

\begin{abstract}
Nossos adolescentes amam, estudam, brigam, trabalham. Batalham com seus corpos, que se esticam e se transformam. Lidam com as dificuldades de crescer no quadro complicado da família moderna. Como se diz hoje, eles se procuram e eventualmente se acham. Mas, além disso, eles precisam lutar com a adolescência, que é uma criatura um pouco monstruosa, sustentada pela imaginação de todos, adolescentes e pais. Um mito, inventado no começo do século 20 , que vingou sobretudo depois da Segunda Guerra Mundial (Calligaris, 2000, p. 9).
\end{abstract}

O trabalho de Philippe Ariès (1978) é exemplar para a compreensão da invenção da infância na sociedade ocidental. Em sua História social da criança e da família esse autor conta como o sentimento acerca da infância (como consciência da particularidade do infantil) foi se elucidando através de duas categorias. Primeiramente, "o sentimento da infância 'engraçadinha"' (Ariès, 1978, p. 22), em que a criança consistia na fonte de divertimento e de relaxamento dos pais e dos adultos em geral "sentimento de paparicação" (Ariès, 1978, p. 100). Em segundo lugar, o "sentimento de exasperação” (Ariès, 1978, p. 20), como negação da paparicação, no qual a criança era alvo de governo por parte dos educadores (eclesiásticos, homens da lei, moralistas e outros) com vista a um disciplinamento satisfatório.

Interessante como o referido autor narra a propiciação da diferenciação da infância e da adolescência, já que inicialmente não se colocam diferenças entre ambas. Na passagem da criança para a fase adulta - a própria noção de fase, de desenvolvimento, é atual, fruto da influência de discursos biologizantes e evolucionistas - surge a escola como espaço potencializador dessa travessia, de tal forma que a separação por idades se formaliza, nas salas de aula, apenas no início do século XIX. É preciso considerar que, etimologicamente, quando do aparecimento do vocábulo na língua portuguesa em meados do século $\mathrm{XV}$, desenvolvimento significava "des-envolver" algo que estivesse envolvido por uma camada ou algo semelhante (Houaiss, 2001). A expressão assumiu outros contornos semânticos, chegando a significar, na contemporaneidade, tanto o grau de civilização de determinado país quanto o nível de habilidades sociais de um indivíduo. "Tem-se a impressão, portanto, de que, a cada época corresponderiam uma idade privilegiada e uma periodização particular da vida humana: a 'juventude' é idade privilegiada do século XVIII, a 'infância', do século XIX, e a 'adolescência', do século XX (Ariès, 1978, p. 48)".

Assim, o século $X X$ apontaria o cenário discursivo ideal para a constante visibilidade da adolescência: nunca se falou tanto acerca da adolescência, que nunca foi tão incessantemente territorializada, traduzida, identificada. Isso reverberou, sobremaneira, no dispositivo jurídico, que passou a compreender a categoria adolescência como um conjunto que reclama uma especificidade dentro do seu próprio sistema (Abramo, 1997).

\section{A EMERGÊNCIA DO ADOLESCENTE POBRE COMO UMA CATEGORIA A SER ASSISTIDA}

Na Europa do século XVIII a família começa a ser eleita como alvo de governo através da invenção da medicina higienista, marcando o desbravamento do saber médico para além do território hospitalar. Reúne-se, para esse fim, todo um conjunto de proliferação de tecnologias políticas que irão investir sobre o corpo, pela via da medicalização, da habitação, da higienização, da escolarização e outras. (Donzelot, 1980). Em relação às classes mais ricas, a intervenção higiênica é pautada por uma lógica normativa, ao passo que em relação às categorias mais pobres o que sobressai é uma lógica normativo-policial (Donzelot, 1980; Gadelha, 1998).

No Brasil, o movimento higienista tomou forma na segunda metade do século XIX, e como é através da doutrinação que a classe médico-higiênica atua, cooptando a população para o modo de vida correto e asséptico da 
higiene, sobre duas categorias principais incide o poder normativo-higiênico: a mulher e a infância - categorias que, em uma sociedade machista e patriarcal, estariam mais vulneráveis aos conselhos médicos; mas foi nos anos 1920 que o movimento higienista brasileiro teve seu apogeu, sobretudo, a partir da formalização da Liga Brasileira de Higiene Mental, em 1923, na cidade do Rio de Janeiro, por Gustavo Riedel. Inicialmente, tal como assinala Lima (2010), o objetivo da Liga "era pensar a melhoria da assistência ao doente mental. Contudo, a partir de 1926, esse objetivo foi cedendo lugar à ideologia eugênica, à profilaxia e à adaptação dos indivíduos por meio da educação" (p. 76). Seguindo desse modo, o movimento exercido pela elite científica pretendia promover 0 saneamento moral do país - replicando, assim, o modelo hegemônico da América Latina baseando-se em teorias racistas, na eugenia e no darwinismo social, de tal forma que se tornaria necessário proceder a uma higienização da sujeira social, que pode ser lida como pobreza. Tal limpeza acaba por criar uma noção de que a degradação moral é particularmente ligada à pobreza e percebida como um problema social que se deve combater.

Como expusemos anteriormente, aquilo que Foucault (2008) nomeou de dispositivos de segurança opera a partir de uma perspectiva de futuro, trabalhando a racionalização dos perigos. Foi sobretudo na virada dos séculos $\mathrm{XIX}$ e $X X$ que esse modelo de governamentalidade foi acionado nos grandes centros urbanos brasileiros. Em um cenário em que se tornam importantes tanto uma gestão dos perigos quanto uma administração do futuro, toma corpo a centralidade da questão da infância/adolescência. A criança pobre e a adolescência abandonada viram discurso (Coimbra, 2001).

A preocupação de que o jovem pobre poderia tornar-se um adulto perigoso colocaria a juventude na ordem do dia, de forma que o jovem começa a ser, estrategicamente, o ponto de dobra onde incide e se incita todo um conjunto de práticas e de normas em relação ao manuseio de suas virtualidades (Foucault, 1987). É nesse cenário discursivo, de incitação do medo, que se torna necessária a intervenção junto a crianças e jovens, como uma estratégia para evitar que estes componham as classes perigosas.
A primeira legislação brasileira a fazer referência específica ao adolescente pobre data do século XX. A Lei Orçamentária de 1921 continha um artigo autorizando o Poder Executivo a organizar a assistência e a proteção à infância abandonada e delinquente segundo determinadas normas. Essa lei exerceu influência nevrálgica no primeiro Código de Menores da América Latina, promulgado no Brasil em 1927 (Muniz-Neto, 2014).

O Código exclui concepções jurídicas consideradas obsoletas pelos juristas do novo século, entre elas, culpabilidade e discernimento. A partir de 1927, o critério estabelecido para a reclusão do menor passou a ser exclusivamente o etário: o menor de 14 anos tornou-se improcessável. O Código também alterou ferramentas como o pátrio poder, fixou a maioridade penal aos 14 anos e fez o Estado assumir a assistência ao menor de idade, proteção que deveria ser pautada por uma perspectiva reeducacional (Muniz-Neto, 2014).

Nesse rearranjo da assistência, o adolescente pobre era forjado no estigma da vítima, sendo narrado exclusivamente por sua negatividade, através da Doutrina da Situação Irregular, pela qual o Estado deve intervir em casos de carência, abandono e delinquência (Lemos, 2012).

Ressaltando genealogicamente as condições de possibilidade, a tessitura do saberpoder em que emergem os Códigos de Menores (considerando-se também o Código de 1979) atrela-se a arranjos discursivos em que o menor é visto como uma doença social e precisa ser corrigido. Desta forma, a menoridade assume um status de alteridade: o menor é, incessantemente, capturado como o outro, como "depósito de uma humanidade alienada" (Žižek, 2010, p. 212).

Escreve Pinheiro (2006, p. 61):

Surgiram, então, expressões institucionais e instituintes de práticas sociais, que viam na coerção um caminho para enfrentar as ações praticadas pelos que eram considerados "delinquentes": a elaboração do primeiro Código de menores da América Latina, que entrou em vigor em $1927 . .$. Inicia-se a era do isolamento, da retirada do convívio social de crianças e adolescentes a quem se atribuía o cometimento de atos considerados infracionais. É o uso de punição como instrumento de correção, pela exclusão 
social, uma forma de neutralizar a ameaça que esses adolescentes representavam para a sociedade.

Não obstante, esse trato de exasperação com a menoridade foi dando lugar a outros engendramentos em meados de 1980. Práticas oriundas de movimentos sociais fomentaram um processo de democratização ao maquinarem um novo contexto brasileiro, criando condições de possibilidade para a emergência de uma constituição que se arroga 0 título de Constituição Cidadã.

Em consonância com o previsto nesta Constituição, o Brasil aprova um novo Código direcionado à adolescência que, tendo por base instituições, tratados, convenções e acordos internacionais, além de uma movimentação social (Gadelha, 1998), assumia uma postura diferenciada em relação aos dois primeiros: passou-se de uma concepção menorista de alguém a ser assistido a uma concepção de sujeito de direitos, em que se asseguram à criança e ao adolescente uma proteção integral e garantias fundamentais. Inaugura-se, assim, a doutrina do adolescente como um sujeito de direitos, "independente de qualquer critério classificatório, tais como origem econômica, idade, estrutura familiar" (Pinheiro, 2006, p. 81). Outra diferenciação do ECA é que este resultou de um conjunto de forças heterogêneas dos movimentos sociais, que por sua vez inaugurou um conjunto de discursos, tornando possíveis enunciados acerca dos direitos sexuais e reprodutivos de adolescentes, a liberdade de expressão e outros.

Ao examinar o ECA (Brasil, 1990) e analisar as medidas de proteção $e$ as medidas socioeducativas, assistimos ao surgimento da noção de vulnerabilidade da adolescência pobre. Uma vez que o adolescente esteja em risco falta de recursos materiais (limitação ou privação de educação, habitação, lazer, cultura, etc.) e afetivos (fragilização ou rompimento dos vínculos familiares e comunitários), - o ECA orienta que sejam tomadas medidas interventivas para que o jovem saia da situação de vulnerabilidade social. As medidas de proteção instituídas pelo ECA corresponderiam aos seguintes aspectos: preservação dos vínculos familiares; integração de família substituta (uma vez esgotadas as tentativas de manutenção/acompanhamento da família de origem); atendimento personalizado/ em pequenos grupos para que o adolescente seja assistido em sua especificidade; uso de abrigo quando necessário, etc. Por sua vez, as seis medidas socioeducativas - advertência, reparação ao dano, prestação de serviço à comunidade, semiliberdade, liberdade assistida e internação - são de caráter sancionatório e educativo para adolescentes que tenham cometido alguma infração. $O$ juiz/juizado computa a medida baseando-se na gravidade do ato infracional cometido pelo adolescente.

Concebemos como uma nova roupagem um movimento atual em que as medidas aplicadas aos adolescentes têm sido cada vez mais permeadas de eufemismos e de um discurso politicamente correto marcado pela obsessão no uso de terminações eufemísticas ("menor" por "adolescente", "infrator" por "socioeducando"). Tal uso retórico às vezes acaba por tamponar as violentas práticas discursivas e não discursivas que permeiam as relações jurídicas e comunitárias com esses adolescentes, os quais ainda são tidos pela comunidade como delinquentes e como menores perigosos e sofrem violências simbólicas e físicas dos familiares. Em situação de privação de liberdade, muitas vezes também sofrem abusos dos educadores sociais. Para pensar como o jovem pobre vem sendo traduzido a partir de discursos tolerantes, ensaiaremos uma aproximação teórica com Duschatzky e Skliar (2001), quanto à formação discursiva "o outro como alguém a tolerar" (p. 134). Teceremos brevemente algumas associações possíveis entre o Estatuto da Criança e do Adolescente e práticas de tolerância à juventude pobre.

$O$ uso dos eufemismos se mostra consonante com a questão da tolerância, na qual se torna necessário tolerar 0 jovem pobre, entendendo-o e encaixando-o com base no controle permanente de suas virtualidades. Torna-se necessário o conhecimento total das práticas cotidianas desse adolescente (com quem ele se relaciona, com quem mora, qual sua renda familiar, se faz uso de contraceptivos ou de drogas, se comete ato infracional, etc.), ou seja, é preciso controlar aquilo que ele poderia vir a ser ou a fazer. Esse constante acompanhamento aparece como objeto de trabalho para as intervenções dos especialistas psicólogos, assistentes sociais, pedagogos e outros - que irão proteger e ressocializar esse adolescente. "O outro como alguém a tolerar" (Duschatzky \& Skliar, 2001, p. 134) seria uma modulação discursiva bastante eufemística, pois 
se vincula ao discurso de aceitação do próximo numa perspectiva por vezes voluntarista; mas parece que o elogio à tolerância, em seu argumento de proteção e de compreensão, é ainda mais devastador por ser mais camaleônico. As medidas socioeducativas, por exemplo, colocam em visibilidade 0 teor educativo, mas mascaram o caráter punitivo que normalmente constitui as práticas de atendimento a esses adolescentes, de tal forma que são enfatizados usos de rótulos eufêmicos, como menor/adolescente, prisão/centro educacional, cela/quarto e guarda/orientador.

De nossa parte, entendemos que esses deslocamentos acabam por aprisionar os adolescentes num perverso lugar de tutela e assujeitamento, de forma que, "silenciados e enredados nas estruturas de dominação as quais eles mesmos desconhecem, continuam a se subjetivar como tutelados, invisíveis e não falantes" (Castro, 2011, p. 300), encobrindo uma violência simbólica atrelada a essas falas conciliatórias e eufemísticas.

Não nos interessa nesse texto fazer julgamentos morais acerca do ECA ou concebêlo como um avanço jurídico ou ainda propor-lhe melhoramentos. Além do mais, apesar das rupturas acima apontadas entre o ECA e os demais códigos que 0 antecederam, concebemos nele também continuidades. Por exemplo, a partir do ECA, mesmo com a doutrina do adolescente enquanto sujeito de direitos e como ser em desenvolvimento, este ainda é vinculado a uma lógica de vitimização mas desta feita ele é vetorizado por uma imagem de vítima não mais individual, mas coletiva. O enfoque muda do menor (e, como tal, perigoso) para um jovem desprovido de condições sociais e emocionais suficientes para seu pleno desenvolvimento biopsicossocial (e como tal, vulnerável - podendo vir a ser perigoso). O ECA (assim como os outros CMs) organiza um controle social a partir de uma terminologia e lei específicas, não superando o paradigma etário e usando de práticas, instituições e políticas de atendimento (Pinheiro, 2006, p.70) para o infrator. Além do mais, destacamos o caráter reiteradamente produtivo de formas e modos de vida presentes nos artigos do ECA e dos estatutos que o antecederam, e corroboramos a ideia de tomá-lo um dispositivo que tem implicações na constituição subjetiva dos indivíduos e na própria invenção da categoria "adolescente pobre". Não julgamos que esta invenção tenha sido processada a partir do ECA, mas sim, que este se soma ao cenário produtivo discursivo.

\section{(IN)CONCLUSÕES SOBRE A QUESTÃO}

A hipossuficiência está na moda. A governamentalidade trabalha a fim de aplacá-la, de devolver aos excluídos de sempre as benesses da atualidade. Inserindo, minimamente, a hipossuficiência dentro de um mercado consumidor - que consome produtos, mas que também consome ideias, serviços e pessoas - as políticas públicas trabalham a fim de desenvolver a autonomia de seus beneficiários: política de cotas nas universidades públicas; dentro do setor jurídico, estatutos específicos (O ECA...); programas raciais de inclusão; inclusão também dos setores especiais dentro da escola regular - enfim, invenção do politicamente correto através de práticas inclusivistas (Muniz-Neto, 2014).

Enquanto a adolescência (pobre) tem sido, estrategicamente, a superfície de contato na qual se incita um conjunto de práticas e de normas em relação ao manuseio de sua vida (a forma correta de se alimentar; a maneira certa de estudar; a descrição das atividades cotidianas; a tradução de suas necessidades; a terapeutização de seus conflitos, etc.), assistimos, cada vez mais, ao aprimoramento de um direcionamento para um trato politicamente correto das práticas de vida desses sujeitos. Torna-se visível que o governo dessa população se insere no embasamento e na operacionalização das políticas públicas.

Assim, pode-se dizer que tanto o ECA quanto os outros códigos de menores estabelecidos no vetor jurídico brasileiro foram direcionados para um tipo específico de usuário: o adolescente pobre. O ECA, por se forjar "na efervescência da luta pelos direitos humanos" (Pinheiro, 2006, p. 81), ao contrário, não pretende se dirigir apenas a uma porção da população de crianças e adolescentes ou fazer menção a uma infância marginal, como o faz a lógica menorista. Neste sentido, o ECA estaria direcionado a toda a população infanto-juvenil, pois se propõe a ser uma lei universal.

Não obstante os termos empregados na contemporaneidade pelos documentos da assistência social, do SUAS e do ECA para referir-se ao adolescente (sujeito protagonista, 
ser em desenvolvimento, etc.), o que ainda parece sustentar a lógica socioassistencial não é, necessariamente, a efetivação de um sujeito de direitos, alicerçada pelo próprio ECA. Consideramos que há ainda um enfoque na população jovem pobre, quando se trata da concretização do Estatuto de 1990: o ECA põe em funcionamento uma política que guarda também semelhanças com a noção preventivista e controladora do início do século $X X$ e das acepções presentes nos códigos de menores, de tal forma que vivenciamos um outro arranjo, com hibridizações entre a situação irregular dos códigos de menores e a lógica do "sujeito de direitos" assumida pelo ECA.

\section{REFERÊNCIAS}

Abramo, H. W. (1997). Considerações sobre a tematização social da juventude no Brasil. Revista Brasileira de Educação. São Paulo, volume especial, (5/6), 25-36.

Ariès, P. (1978). A História social da criança e da família. Rio de Janeiro: Guanabara.

Austin, J. L. (1971). Cómo hacer cosas con palabras. Barcelona: Paidós.

Benevides, P. S. (2011). As retóricas contemporâneas e a significação da educação inclusiva. Psicologia \& Sociedade, 23(2), 248-253.

Brasil. (1988). Constituição Federal. Brasília, Senado Federal: Centro Gráfico.

Brasil. (1990). Estatuto da Criança e do Adolescente. Brasília: CBIA.

Brasil. (2012). Ministério do Desenvolvimento Social e Combate à Fome - MDS. Brasília - DF, Brasil. Recuperado em 31 de maio, 2012, de http://www.mds.gov.br/assistenciasocial/protecaob asica/servicos/projovem.

Butler, J. (2008). Problemas de gênero: Feminismo e subversão da identidade. (2. ed.). Rio de Janeiro: Civilização Brasileira.

Calligaris, C. (2000). A adolescência. São Paulo: Publifolha.

Candiotto, C. (2012). Disciplina e segurança em Michel Foucault: a normalização e a regulamentação da delinquência. Psicologia e Sociedade. 24(n. especial), 18-24).

Castel, R. (2008). As metamorfoses da questão social - uma crônica do salário. (7. ed). Petrópolis, RJ: Vozes.

Castro, L. R. (2011). Os jovens podem falar? Sobre as possibilidades políticas de ser jovem hoje. In J. Dayrell \& M. I. C. Moreira \& M. Stengel (Orgs.). Juventudes contemporâneas: um mosaico de possibilidades (pp. 299-324). Belo Horizonte: PUC.
Coimbra, C. M. B. (2001). Os especialistas da infância e da juventude: produzindo verdades competentes. Paideia, 11(20), 85-88.

Donzelot, J. (1980). A Polícia das Famílias. Rio de Janeiro: Graal.

Duschatzky, S., \& Skilar, C. (2001). O nome dos outros. Narrando a alteridade na cultura e na educação. In J. Larrosa, \& C. Skliar. (Orgs.). Habitantes de Babel: Políticas e poéticas da diferença. Belo Horizonte: Autêntica.

Foucault, M. (1987). Vigiar e Punir: nascimento da prisão. Petrópolis: Vozes.

Foucault, M. (1992). A governamentalidade. In M. Foucault. Microfísica do poder (pp. 277-293). Rio de Janeiro: Graal.

Foucault, M. (2002). Os Anormais. São Paulo: Martins Fontes.

Foucault, M. (2008). Segurança, Território, População. São Paulo: Martins Fontes.

Gadelha, S. (1998). Subjetividade e menoridade: acompanhando o devir dos profissionais do social. São Paulo: Anna Blume; Fortaleza: Secretaria da Cultura e Desporto.

Gadelha, S. (2013) Empresariamiento de la sociedad y el gobierno de la infancia pobre. Revista Colombiana de Educación. Bogotá, Colombia, 65(2), 215-238.

Hillesheim, B. e Cruz, L. R. (2008). Risco, vulnerabilidade e infância: algumas aproximações. Psicologia \& Sociedade. 20(2), (192-194).

Lemos, F. C. S. (2012) Práticas de governo das crianças e dos adolescentes propostas pelo UNICEF e pela UNESCO: inquietações a partir das ferramentas analíticas legadas por Foucault. Psicologia e Sociedade. 24(n. especial), 52-59.

Lima, A. F. (2010). Metamorfose, anamorfose e reconhecimento perverso: a identidade na perspectiva da Psicologia Social Crítica. São Paulo: FAPESP, EDUC.

Lobo. L. F. (2012). Pesquisar: A Genealogia de Michel Foucault. In T. M. G. Fonseca, M. L. Nascimento, C. Maraschin. Pesquisar na diferença: um abecedário (pp 13-19). Porto Alegre: Sulina.

Muniz-Neto, J. S. (2014). Em Defesa da Sociedade: práticas de tutela à menoridade na Fortaleza Belle Époque. Dissertação de Mestrado, Departamento de Psicologia, Universidade Federal do Ceará, Ceará.

Oliveira, F.; (2010). Apresentação. In R. Braga, \& C. Rizek. (Orgs.). Hegemonia as avessas: economia, política e cultura na era da servidão financeira (pp. 181-252). São Paulo: Boitempo.

Pinheiro, A. (2006). Criança e Adolescente no Brasil: porque o abismo entre a lei e a liberdade. Fortaleza: UFC.

Pontes, A. K. (2011). Juventude e risco: problematizando o sentindo construído por jovens sobre esta relação. Dissertação de Mestrado, 
Departamento de Psicologia, Universidade Federal do Ceará, Ceará.

Žižek, S. (2010). Prójimos y otros monstruos: un alegato en favor de la violencia ética. In S. Žižek, E. L. Santner, \& K. Reinhard. (Orgs.). El prójimo: tres indagaciones en teologia política (pp. 7-14). Buenos Aires: Amorrortu.

João Silveira Muniz Neto: psicólogo, mestre em Psicologia pela Universidade Federal do Ceará, Brasil.

Aluísio Ferreira de Lima: psicólogo, com pós-doutorado, doutorado e mestrado (2005) em Psicologia Social pela Pontifícia Universidade Católica de São Paulo; professor adjunto III do Departamento de Psicologia da Universidade Federal do Ceará; professor permanente do Programa de Pós-Graduação em Psicologia, do Programa de PósGraduação em Saúde da Família e do Mestrado Profissional em Saúde da Família (UFC/RENASF), Brasil.

Luciana Lobo Miranda: graduada em Psicologia pela Universidade Federal do Ceará; mestre e doutora em Psicologia Clínica pela Pontifícia Universidade Católica do Rio de Janeiro; professora associada I do Departamento de Psicologia da Universidade Federal do Ceará e do Programa de Pós-Graduação (Mestrado) em Psicologia da mesma universidade, Brasil.

Luara da Costa França: psicóloga; mestre em Psicologia pela Universidade Federal do Ceará; bolsista CAPES, Brasil. 